\title{
A CONSTRUÇÃO DO CONHECIMENTO ORTOGRÁFICO NO CONTEXTO DAS INTERAÇÕES ADULTO-CRIANÇA
}

\begin{abstract}
ELAINE C. R. GOMES VIDAL
Universidade São Judas Tadeu (USJT). Mestre e Doutoranda em Psicologia, Linguagem

e Educação pela Faculdade de Educação da USP. Grupo de Pesquisa Novas Arquiteturas Pedagógicas. Docente da Universidade São Judas Tadeu. Brasil. ORCID: 0000-0003-0320-217. E-mail: elainecrgvidal@gmail.com

\section{SILVIA M. GASPARIAN COLELLO}

Universidade de São Paulo (USP). Doutora e Livre Docente pela Faculdade de Educação da USP. Docente da Pós-graduação na FEUSP. Grupos de Pesquisa: NAP e CEMOrOc. Brasil.

ORCID: 000-002-8813-8092. E-mail: silviacolello@usp.br.www.silviacolello.com.br
\end{abstract}




\section{A CONSTRUÇÃO DO CONHECIMENTO ORTOGRÁFICO NO CONTEXTO DAS INTERAÇÕES ADULTO-CRIANÇA}

Partindo do problema do desempenho insuficiente nas habilidades de escrita de estudantes brasileiros, o artigo tem o objetivo de apresentar uma pesquisa sobre o papel da interação entre adulto e criança na construção do conhecimento ortográfico. Para tanto, recupera parte de um estudo de caso longitudinal em curso, realizado com alunos de uma escola privada em Santos/SP, em cinco etapas entre o $2^{\circ}$ e o $4^{\circ}$ ano do Ensino Fundamental (período em que o escrever corretamente passa a ser um foco especial de conquista cognitiva e, consequentemente, de ensino). Valendo-se do referencial teórico dos estudos psicogenéticos e histórico-culturais (a concepção das crianças como sujeitos ativos e protagonistas da aprendizagem; a língua como prática social e a interação como favorecimento da aprendizagem), o estudo centrou-se na problematização, feita de modo interativo, sobre as formas de escrever. Realizada a partir de dois eixos de atividade (ditado de palavras e reescrita de contos), a coleta de dados visou apreender a compreensão das estratégias infantis ou das reflexões empreendidas na busca de referências para a correção da escrita, chegando, assim, a quatro categorias: a escrita validada pela pauta sonora, a validação da escrita com base em alguém mais experiente (um "interlocutor autorizado"), o apoio na imagem visual da palavra e, finalmente, a evocação da norma ortográfica. Embora essas categorias estejam sempre presentes nos diferentes estágios de escolaridade (e de conhecimento), a análise quanti-qualitativa dos dados evidenciou o predomínio de umas sobre as outras que, em movimentos ascendentes e descendentes, marcam um percurso de crescente autonomia e consciência metalinguística. A partir da compreensão sobre os processos cognitivos do conhecimento ortográfico - a variedade das estratégias de escrita ou de validação da escrita e caminhos de progressão -, é possível vislumbrar algumas implicações pedagógicas que subsidiam a revisão de práticas pedagógicas.

Palavras-chave: Língua escrita. Processos cognitivos. Ortografia. Práticas interativas.

\section{THE CONSTRUCTION OF ORTHOGRAPHIC KNOWLEDGE IN THE CONTEXT OF ADULT- CHILD INTERACTIONS}

Considering the issue of the poor performance of Brazilian students when it comes to writing skills, this article aims to present a research about the role of the interaction between adults and children in the construction of orthographic knowledge. In order to do so, it recovers part of an ongoing longitudinal case study which took place in Santos/SP with students at a private school in 5 stages between the 2nd and 4th grade of Elementary School (period when writing correctly becomes the focus of cognitive achievement; therefore, focus of the teaching). Using the theoretical framework of psychogenetic and historical-cultural studies (the concept of children as active subjects and the student-centered learning; language as social practice and interaction to benefit the learning experience), the study focused on the problematization of different writing ways. Data collected from two axes of activity (a dictation and from the rewriting of short stories) aimed to apprehend the understanding of children's strategies or reflections undertaken in the search for references for the correction of writing, coming, as a consequence, to four different categories: the writing validated by the sound score, the validation of the writing based on someone more experienced

\section{plurais}


(an "authorized interlocutor"), the support in the visual image of the word and, finally, the evocation of the orthographic rules. Although these categories are always present in the different stages of education (and knowledge), the quantitative and qualitative analysis of the data showed the predominance of one over the other which, in upward and downward movements, mark a path of increasing autonomy and metalinguistic awareness. From the understanding of the cognitive processes of orthographic knowledge the variety of writing strategies or writing validation and progression paths - it is possible to glimpse some pedagogical implications that support the revision of pedagogical practices.

Keywords: Written language. Cognitive processes. Orthography. Interactive practices.

\section{LA CONSTRUCCIÓN DEL CONOCIMIENTO ORTOGRÁFICO EN EL CONTEXTO DE LAS INTERACCIONES ADULTO-NIÑO}

Partiendo del problema del rendimiento insuficiente en las habilidades de escritura de los estudiantes brasileños, el artículo tiene como objetivo presentar una investigación sobre el papel de la interacción entre adultos y niños en la construcción del conocimiento ortográfico. Con este fin, recupera parte de un estudio de caso longitudinal en curso, llevado a cabo con estudiantes de una escuela privada en Santos/ $\mathrm{SP}$, en cinco etapas entre el segundo y cuarto año de educación primaria (período en el que lo acto de escribir correctamente se convierte en un enfoque especial del logro cognitivo y, en consecuencia, de la enseñanza). Partiendo del marco teórico de los estudios psicogenéticos e histórico-culturales (la concepción de los niños como sujetos activos y protagonistas del aprendizaje; el lenguaje como práctica social y la interacción como un conducto para el aprendizaje), el estudio se centró en la problematización, hecha de manera interactiva, sobre las formas de escribir. Basado en dos ejes de actividad (dictado de palabras y reescritura de cuentos), la recopilación de datos tuvo como objetivo comprender la estrategia de los niños o reflexiones emprendidas en la búsqueda de referencias para la corrección de la escritura, alcanzando así cuatro categorías: la escritura validada por la sonoridad; la validación de la escritura basada en alguien más experimentado (un "interlocutor autorizado"), el soporte en la imagen visual de la palabra y, finalmente, la evocación de la norma ortográfica. Aunque estas categorías siempre están presentes en las diferentes etapas de la educación (y el conocimiento), el análisis cuantitativo y cualitativo de los datos mostró el predominio de uno sobre el otro, que en los movimientos ascendentes y descendentes, marcan un camino de mayor autonomía y conciencia metalingüística. A partir de la comprensión de los procesos cognitivos del conocimiento ortográfico (la variedad de estrategias de escritura o validación de escritura y caminos de progresión), es posible vislumbrar algunas implicaciones pedagógicas que respaldan la revisión de las prácticas pedagógicas.

Palabras clave: lenguaje escrito. Procesos cognitivos. Ortografía. Prácticas interactivas.

\section{plurais}

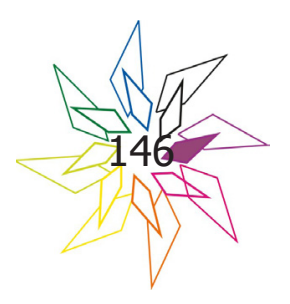




\section{A CONSTRUÇÃO DO CONHECIMENTO ORTOGRÁFICO NO CONTEXTO DAS INTERAÇÕES ADULTO-CRIANÇA}

\section{Introdução}

A escola, como instituição social responsável pela transmissão cultural intergeracional, tem, entre suas principais funções, o ensino da língua escrita. Considerada uma das aprendizagens primordiais a todo estudante, a escrita constitui-se, a um só tempo, objeto de ensino e instrumento de aprendizagem (COLELLO, 2012). Afinal, além de os alunos precisarem aprender a ler e escrever para a sua constituição pessoal, social e política, o conhecimento da escrita é uma importante via de acesso para outros conhecimentos.

Apesar da valorização do ensino da escrita ser uma constante em diferentes períodos da história da educação, a prática pedagógica foi consubstanciada de diversas formas e com diferentes ênfases. No fulcro dessa diversificação está o modo como, em diferentes momentos e por diferentes autores, foi concebida essa aprendizagem, ora mais centrada em aspectos notacionais (o como se escreve), ora na dimensão discursiva (o como se organiza a linguagem escrita), ambos inerentes à atividade de escrever. Barcellos (2013), ao analisar a história do ensino de língua no Brasil, identifica três encaminhamentos pedagógicos distintos. O modelo Prescritivo prioriza a norma culta, levando o aluno a substituir seus padrões linguísticos por produções pautadas em regras de suposta correção linguística, como no Brasil Colônia (com o propósito de impor aos indígenas um modo correto de falar), ou no Império (que se valia do modelo europeu de educação). O modelo Descritivo, vinculado ao surgimento da linguística como ciência no período da República, sem a pretensão de interferir no comportamento linguístico do sujeito, chama a atenção para os modos de funcionamento da língua. Finalmente, em meados do século XX, na esteira dos estudos psicogenéticos e histórico-culturais, o modelo Produtivo postula o ensino de novas habilidades linguísticas, ampliando a apropriação da língua, as suas possibilidades de uso, de reflexão metalinguística e de trânsito na cultura escrita. Nessa perspectiva, a exploração dos aspectos notacionais e discursivos aparecem de modo articulados e equilibrados.

Em que pese a orientação oficial por um ensino produtivo, os indicadores insatisfatórios obtidos pelos alunos brasileiros em diferentes avaliações (Prova Brasil e PISA, entre outros) de-

\section{plupais}


monstram que a aprendizagem da língua está aquém das metas desejáveis, o que se explica por fatores históricos, políticos, sociais, econômicos e geográficos, com destaque para a dimensão pedagógica (COLELLO, 2012).

A esse respeito, vale apontar para os descompassos, bastante frequentes, entre o ensino e a aprendizagem e entre as diretrizes curriculares e a prática pedagógica. No primeiro caso, como se sabe, o aprendido nem sempre corresponde ao ensinado e este, por sua vez, pode não levar em conta os saberes já conquistados pelos sujeitos ou as dinâmicas de construção cognitiva. Nas palavras de Weisz e Sanchez (2001, p. 65):

O processo de aprendizagem não responde necessariamente ao processo de ensino, como tantos imaginam. Ou seja, não existe um processo único de "ensino-aprendizagem", como muitas vezes se diz, mas dois processos distintos: o de aprendizagem, desenvolvido pelo aluno, e o de ensino, pelo professor. São dois processos que se comunicam, mas não se confundem: o sujeito do processo de ensino é o professor, enquanto o do processo de aprendizagem é o aluno.

O segundo caso - distanciamento entre as diretrizes pautadas pelo modelo Produtivo e as práticas pedagógicas - parece ser uma constante, tendo em vista que a singularidade das instituições e a condição histórica e idiossincrática dos professores marcam um estado nebuloso das próprias concepções de ensino. Em função disso, a análise da escola contemporânea demonstra como os três modelos - Prescritivo, Descritivo e Produtivo - convivem simultaneamente, com diferentes ênfases e graus de influência sobre o desenvolvimento do currículo. Em muitos casos, o foco excessivo na metalinguagem descontextualizada compromete os efetivos propósitos comunicativos, prejudicando o sentido da aprendizagem, como destaca Geraldi (2006, p. 45):

[...] o mais caótico da situação atual do ensino de língua portuguesa em escolas de primeiro grau consiste precisamente no ensino, para alunos que nem sequer dominam a variedade culta, de uma metalinguagem de análise dessa variedade - com exercícios contínuos de descrição gramatical, estudo de regras e hipóteses de análise de problemas que mesmo especialistas não estão seguros de como resolver.

Esse cenário justifica o interesse em compreender, ainda mais e melhor, o modo como as crianças aprendem a leitura e a escrita e, por essa via, repensar os procedimentos de ensino. No caso da presente pesquisa, entendendo a dimensão notacional como parte integrante do complexo

\section{plurais}


desafio de produção textual e de formação do usuário competente da escrita, o objetivo é analisar a construção da ortografia. Apresentando resultados parciais de uma investigação mais ampla ${ }^{1}$, os dados analisados neste artigo procuram apresentar especificamente o papel da interação entre adultos e crianças na especificidade dessa trajetória cognitiva. Para tanto, partindo da explicitação da estrutura e metodologia adotadas na pesquisa, faremos uma exposição das categorias de respostas infantis mediadas pela intervenção da pesquisadora. Na sequência, será apresentada, através de análise quanti-qualitativa, a progressão dos alunos ao longo de três anos de escolaridade. Finalmente, a título de conclusão, serão discutidas possíveis implicações pedagógicas decorrentes desses achados.

\section{Metodologia da pesquisa e perspectivas de análise}

A pesquisa foi desenvolvida em uma escola da rede privada, situada em Santos/SP. A instituição, cuja comunidade é formada por crianças e famílias de classe média, apresenta-se como escola construtivista. O Projeto Político-Pedagógico pauta-se pelo ensino da língua baseado em práticas sociais de leitura e escrita, com atividades didáticas elaboradas pela própria equipe pedagógica.

A pesquisa, realizada em cinco etapas com um intervalo de 6 meses entre si $\left(1^{\circ}\right.$ semestre do 20 ano; $2^{\circ}$ semestre do $2^{\circ}$ ano $; 1^{\circ}$ semestre do $3^{\circ}$ ano $; 2^{\circ}$ semestre do $3^{\circ}$ ano e $1^{\circ}$ semestre do $4^{\circ}$ ano do Ensino Fundamental), assume caráter longitudinal, estudando um grupo de 12 a 18 sujeitos (dependendo da variação no número de alunos da turma). A investigação, portanto, ocupou-se de um período escolar em que as crianças, tendo dominado o sistema alfabético, passam a enfrentar os desafios ortográficos com maior frequência. A esse respeito, vale lembrar que

Se na história da humanidade os sistemas de escrita alfabética surgiram antes das normas ortográficas, algo semelhante ocorre no desenvolvimento individual. A criança inicialmente se apropria do sistema alfabético: num processo gradativo, descrito pelas pesquisas da psicogênese da escrita, ela aos poucos domina a "base alfabética". [...] O que o aprendiz nessa fase ainda não domina, porque desconhece, é a norma ortográfica. Ele pode já ter notado algumas incongruências de nosso sistema alfabético, $[\ldots]$ mas ainda não internalizou as formas escritas que a norma ortográfica convencionou serem as únicas autorizadas. (MORAIS, 2003, p. 20-21)

Para analisar os procedimentos de interação entre adulto e criança, as cinco etapas de coleta de dados mantiveram os mesmos procedimentos, incidindo sobre dois tipos de atividades realizadas individualmente, coletados respectivamente em duas sessões na mesma semana:

1 Tese de doutorado, "A aprendizagem da ortografia sob o viés das práticas interativas”, de Elaine Cristina R. Gomes Vidal, em fase final de elaboração, a ser apresentada na Faculdade de Educação da USP em 2020. A pesquisa original procura compreender a construção do conhecimento ortográfico a partir de diferentes etapas de aprendizagem, contextos de produção da escrita e modos de interação.

\section{plupais}


a) Escrita de palavras: ditado individual de uma lista de palavras contextualizadas pela leitura prévia - feita pela pesquisadora - de um conto de fadas (“A princesa e o grão de ervilha”).

As palavras selecionadas para a lista a ser ditada para as crianças obedeceram ao critério das categorias de dificuldades ortográficas. Entre tantas classificações possíveis, para fins deste trabalho, optou-se pela classificação proposta por Nóbrega (2013): regularidades diretas (subdivididas em interferência da fala na escrita; oposição entre consoantes surdas e sonoras e representação de sílabas não canônicas); regularidades contextuais e irregularidades. Para cada um desses critérios foram selecionadas três dificuldades ortográficas diferentes, elegendo-se uma palavra para cada uma delas. Desta forma, chegou-se à seguinte seleção de palavras.

Quadro 1 - Critérios de seleção das palavras do conto que foram ditadas

\begin{tabular}{|c|c|c|c|}
\hline Categoria da dificuldade & & Dificuldade ortográfica & $\begin{array}{c}\text { Palavras seleci- } \\
\text { onadas }\end{array}$ \\
\hline \multirow{3}{*}{$\begin{array}{l}\text { Regularidade - } \\
\text { Interferência da fala na escrita }\end{array}$} & 1 & Troca de $-\mathrm{E}>-\mathrm{I}$ & Príncipe \\
\hline & 2 & Troca de $-\mathrm{L}>-\mathrm{U}$ & Calcanhar \\
\hline & 3 & $\begin{array}{l}\text { Ditongação em sílabas travadas por /s/ } \\
\text { (acréscimo de - I) }\end{array}$ & Vez \\
\hline \multirow{3}{*}{$\begin{array}{l}\text { Regularidade - } \\
\text { Oposição surda/sonora }\end{array}$} & 4 & $\mathrm{P} / \mathrm{B}$ & Sapatos \\
\hline & 5 & $\mathrm{~T} / \mathrm{D}$ & Tempestade \\
\hline & 6 & $\mathrm{~F} / \mathrm{V}$ & Certificar \\
\hline \multirow{3}{*}{$\begin{array}{l}\text { Regularidade - } \\
\text { Representação de sílabas não } \\
\text { canônicas }\end{array}$} & 7 & $\begin{array}{l}\text { Omissão ou substituição da consoante } \\
\text { líquida do ataque }\end{array}$ & Grão \\
\hline & 8 & $\begin{array}{l}\text { Inversão da consoante líquida do ata- } \\
\text { que ou da consoante da coda }\end{array}$ & Encontrara \\
\hline & 9 & Omissão do H em dígrafos & Ervilha \\
\hline \multirow{3}{*}{ Regularidade contextual } & 10 & $\mathrm{M}$ antes de $\mathrm{P}$ e $\mathrm{B}$ & Relâmpago \\
\hline & 11 & $\mathrm{R} / \mathrm{RR}$ & Horrível \\
\hline & 12 & $\mathrm{~S} / \mathrm{SS}$ & Disse \\
\hline \multirow[b]{3}{*}{ Irregularidade } & 13 & $\mathrm{CH} / \mathrm{X}$ em contextos arbitrários & Colchões \\
\hline & 14 & G/J em contextos arbitrários & Exigente \\
\hline & 15 & $\begin{array}{l}\mathrm{C} / \mathrm{C} / \mathrm{S} / \mathrm{SS} / \mathrm{SC} / \mathrm{XC} \text { em contextos } \\
\text { arbitrários }\end{array}$ & Nascença \\
\hline
\end{tabular}

\section{plurais}


b) Reescrita individual de um texto: reescrita de um texto conhecido, já utilizado na sessão anterior (contextualizado, portanto, pela leitura prévia da pesquisadora), com o propósito de ler o texto elaborado para outra turma (consigna dada como garantia de um contexto de produção e de um destinatário para nortear a escrita).

Em cada sessão, gravada em vídeo e posteriormente transcrita, foram utilizadas três estratégias para a coleta de dados: observação participante (com interações problematizadoras, previamente previstas, com o objetivo de gerar reflexão sobre a ortografia das palavras), observação não-participante (com o objetivo de captar os mecanismos de decisão da criança por uma determinada grafia) e análise documental (considerando o processo interlocutivo e a produção final).

Para se evitar, por um lado, intervenções em todas as escritas (o que poderia tornar a tarefa cansativa para as crianças), ou, por outro, que cada intervenção fosse vista pelos alunos como um indício de que a palavra estava grafada de modo incorreto (o que poderia ocorrer caso fossem feitas intervenções em todas as situações de erro), optou-se por um procedimento padronizado de intervenções nas sessões do ditado das cinco etapas de coleta. A cada dificuldade ortográfica, a pesquisadora escolheu uma das três palavras da lista para fazer a intervenção. No que diz respeito ao foco da intervenção, a escolha recaiu prioritariamente, mas não exclusivamente, sobre palavras que continham erros ortográficos. Nos casos em que mais de uma palavra da mesma categoria contivesse erro, ou que nenhuma das três os apresentasse, a escolha foi aleatória.

Todas as intervenções foram realizadas após o término do ditado ou da reescrita. Durante sua produção, a pesquisadora manteve-se o mais "neutra" possível, sempre "devolvendo" à criança as perguntas que eventualmente surgiram, respondendo, por exemplo: "Com que letra você acha que é?"; "Escreva do seu melhor jeito" etc.

Na medida do possível, as intervenções apoiaram-se em consignas-padrão (problematizações) que já induziam a criança à reflexão sobre a natureza do erro ortográfico, conforme o Quadro a seguir.

\section{plurais}


Quadro 2 - Padrão das intervenções feitas na escrita de lista de palavras

\begin{tabular}{|c|c|c|}
\hline & $\begin{array}{l}\text { Categoria da difi- } \\
\text { culdade }\end{array}$ & Intervenções planejadas \\
\hline 1 & $\begin{array}{l}\text { Interferência da fala } \\
\text { na escrita }\end{array}$ & $\begin{array}{l}\text { "Você escreveu [palavra X] do jeito que a gente fala. Será que existem } \\
\text { palavras que a gente fala de um jeito e escreve de outro? Essa poderia } \\
\text { ser uma delas?" }\end{array}$ \\
\hline 2 & $\begin{array}{l}\text { Oposição surda/ } \\
\text { sonora }\end{array}$ & $\begin{array}{l}\text { "Você escreveu [palavra X] assim [mostrar à criança sua própria es- } \\
\text { crita]. Eu vou te mostrar como se escreve uma outra palavra [mostrar à } \\
\text { criança a escrita convencional de uma outra palavra contendo a silaba } \\
\text { que ela errou, na mesma posição]. Observando essa outra palavra, você } \\
\text { mudaria alguma coisa na sua escrita? }\end{array}$ \\
\hline 3 & $\begin{array}{l}\text { Representação de sí- } \\
\text { labas não canônicas }\end{array}$ & $\begin{array}{l}\text { "Se eu disser que nessa palavra está faltando uma letra [nos casos de } \\
\text { omissão; nos casos de substituição, dizer que tem uma letra errada; se } \\
\text { for caso de inversão, dizer que tem letras com a posição trocada e, nos } \\
\text { casos de acréscimo, dizer que tem uma letra a mais], você consegue } \\
\text { descobrir qual é?" }\end{array}$ \\
\hline 4 & $\begin{array}{l}\text { Regularidade con- } \\
\text { textual }\end{array}$ & $\begin{array}{l}\text { "Olhando para as letras que vêm antes e depois do [mostrar a letra erra- } \\
\text { da], você mudaria o jeito de escrever a palavra?" }\end{array}$ \\
\hline 5 & Irregularidade & $\begin{array}{l}\text { "Uma outra criança escreveu essa palavra assim [mostrar a escrita con- } \\
\text { vencional]. É possível escrever assim? Quem você acha que acertou? } \\
\text { Por quê?" }\end{array}$ \\
\hline
\end{tabular}

Já nas sessões de reescrita de textos das cinco etapas, a pesquisadora buscou, no texto da criança, uma palavra com cada tipo de dificuldade ortográfica para realizar a intervenção (ainda que não fossem palavras presentes na lista da primeira entrevista). Mais uma vez, privilegiou-se, sempre que possível, palavras escritas com erros ortográficos. As intervenções seguiram o mesmo padrão das consignas propostas nas sessões de ditado. Na escrita textual, porém, outra dificuldade ortográfica poderia surgir: problemas na segmentação (hipo ou hipersegmentação). Nesse caso, a pesquisadora fez intervenções como: "Nesta linha, deveriam existir [X] palavras. Vamos contar quantas tem? Por que será que tem X [colocar a quantidade] palavras a mais [ou a menos]? O que você mudaria?

Com esses procedimentos, buscou-se promover reflexões pertinentes para a compreensão sobre os processos infantis de construção do conhecimento ortográfico.

\section{plurais}


Para fins de análise, buscou-se, nas respostas para as interações com o adulto, estratégias de referência ou de reflexão para a correção linguística, a evolução longitudinal ao longo das cinco etapas e a comparação entre índices de desempenho nos dois tipos de atividades (palavras ditadas e reescrita de textos).

\section{Respostas infantis às interações com o adulto}

Em uma perspectiva que privilegia a construção do conhecimento, mais do que observar o resultado final, importa compreender o percurso que levou até ele. Por trás dos "erros" infantis, é preciso identificar a lógica que os subsidia. Tal como as hipóteses sobre a escrita que as crianças desenvolvem antes de se apropriarem da base alfabética, é razoável supor que, antes de se apropriarem das normas ortográficas, elas também realizam tentativas lógicas de escrever "corretamente", tentativas que, longe de ser aleatórias, têm a sua lógica ou razão de ser.

Do ponto de vista heurístico, é muito mais rentável supor que tudo o que a criança diz, tudo o que faz, quando fala ou quando se cala, tem motivo. Busquemos o sentido de suas palavras e de seus silêncios. E, principalmente, esqueçamos por um momento que nós "já sabemos" as respostas; enfim, as respostas interessam menos que o caminho para se chegar a elas (FERREIRO, 2001, p. 24)

Sob esta óptica, antes de analisar o quanto as interações com a pesquisadora levaram os alunos a modificar o modo como escreviam, importa considerar as respostas que as crianças deram às intervenções feitas, o que permitiu o delineamento de quatro categorias a partir de tendências comuns nas justificativas evocadas pelos alunos.

\section{a) Escrita a partir da pauta sonora}

Embora a escrita não seja um código com correspondência biunívoca entre grafemas e fonemas, as crianças recém-alfabetizadas, que vêm de um processo intenso de fonetização da escrita para compreensão da base alfabética, tendem a buscar uma regularidade nessa relação. Segundo Nóbrega (2013), é comum que crianças, nessa fase, escrevam operando com o valor de base dos grafemas, ou seja, atribuindo a cada letra somente aquele fonema que ela representa com maior frequência. Seguindo essa tendência, as crianças justificaram sua escrita (bem como sua posterior opção por alterá-la ou não a partir da intervenção realizada) relacionando os grafemas ao modo como o "escutam". Em algumas das respostas dessa categoria, essa regularidade foi buscada pelo critério de valor de base das letras utilizadas. Em outras, embora não utilizassem o valor de base, a

\section{plurais}


pauta sonora continuava sendo o fator de maior influência na decisão sobre o modo de grafar as palavras, orientando também as reflexões metalinguísticas. Eis um exemplo dessa categoria no ditado:

[Maitê escreve "sertificar" para "certificar" e a pesquisadora diz que vai escrever outra palavra para que ela observe e veja se, a partir dela, quer mudar sua escrita. A pesquisadora, então, escreve "cebola", de modo a abrir outra possibilidade de escrita para o fonema inicial da palavra em questão].

P: E então, eu escrevi cebola assim. Você acha que essa palavra ajuda você a escrever certificar? M: O que tem a ver "certificar" com "cebola"? "Certificar..." [Fica pensativa por alguns segundos]. Acho que você está pensando que o meu jeito está errado, porque tem som de C no começo. Mas gato tem som de GA e é com G, não é com H. Então, está diferente do som, mas está certo. E acho que cebola é assim [escreve SEBOLA], porque do jeito que você escreveu, fica "QUEBOLA".

$1^{\text {a }}$ etapa de coleta de dados - Ditado de palavras

Como exemplo típico dessa categoria, Maitê demonstra claramente que opera com o valor de base dos grafemas, utilizando $\mathrm{S}$ para o fonema /s/ e atribuindo ao $\mathrm{C}$ o fonema $/ \mathrm{k} /$. Sua resposta traz à tona, ainda, uma confusão comumente encontrada na escrita de crianças recém-alfabetizadas, com utilização do H para representação da sílaba "GA”. Maitê explicita como o princípio acrofônico interfere nessa decisão, ou seja, como o nome da letra $\mathrm{H}$ pode induzir ao erro nesse caso. Por estar segura da utilização do valor de base, a aluna não aceita modificar sua escrita original.

[Laura escreve "diverdade" para "de verdade". A pesquisadora mostra à aluna a linha que contém esse erro, onde se lê: "para saber ce era uma princesa diverdade"]

P: Nesta linha, deveriam existir 8 palavras. Vamos contar quantas tem? [Contam juntas e encontram 7]. Por que será que tem uma palavra a menos? O que você mudaria?

L: Para saber... é separado, porque é para saber alguma coisa, entendeu? É separado. Se era... podia ser junto? [Escreve "ceera"]. Mas ia ser estranho, ia ficar dois "E" juntos. E a gente fala "se era", a gente fala assim, dá pra ouvir. Uma é sozinho mesmo, porque é um número. Princesa também é sozinho. Uma princesa. E “diverdade” é sozinho também, não pode ser junto com princesa. Eu não sei porque tinham que ser oito, porque se a gente prestar atenção em como a gente fala, dá pra perceber que são sete mesmo.

$1^{\mathrm{a}}$ etapa de coleta - Reescrita de texto

\section{plurais}


Na reescrita de textos individuais, essa categoria de respostas também apareceu. Um exemplo é o caso de Laura que, tendo cometido um erro de segmentação, justifica-o com base na sonoridade.

Como se trata de outra natureza de dificuldade ortográfica (segmentação), Laura utiliza também outros critérios para justificar sua escrita: a semântica ("uma é sozinho porque é um número"); a recusa à repetição de letras, provavelmente um resquício de hipóteses anteriores à escrita alfabética, quando as crianças não admitem duas letras iguais lado a lado ("ia ficar estranho, ia ficar dois E juntos"). Note-se, porém, que é a pauta sonora que predomina em suas justificativas (“a gente fala assim"; "dá pra ouvir"; "se a gente prestar atenção em como a gente fala").

\section{b) Escrita validada por um "interlocutor autorizado"}

Na segunda categoria de respostas, encontram-se os casos em que as crianças, para justificarem as suas escritas, baseiam-se predominantemente na escrita de outra pessoa (supostamente “interlocutores autorizados", que se constituem como referências para a própria escrita, geralmente a professora, mas também a pesquisadora, a mãe ou uma criança mais adiantada), tanto para explicarem suas opções originais, como para justificarem as decisões de modificação. A escrita de Elias é um exemplo representativo dessa categoria:

[Elias escreve "tenpestade" para "tempestade"].
P: Você escreveu tenpestade assim [indica a escrita de Elias]. Eu vou escrever aqui a palavra
"tempo" [escreve "tempo" de modo convencional]. Você acha que a palavra "tempo" ajuda você
a escrever "tempestade"?
E: Bom, elas começam igual, e eu escrevi o começo de um jeito, e você escreveu de outro. Eu
pus o N aqui e você pôs o M. Como você já sabe escrever certo e eu ainda estou aprendendo, é
melhor eu arrumar a minha. [Escreve "tempestade"].
$5^{\text {a etapa de coleta de dados - Ditado de palavras }}$

Elias identificou a diferença entre a sua escrita e a da pesquisadora e, mesmo sem fazer nenhuma reflexão metalinguística ou menção às normas linguísticas e ortográficas, optou por endossar o modo de escrita da pesquisadora, que lhe pareceu mais experiente para orientar sua própria escrita. 
No exemplo abaixo, Aline, valendo-se de uma justificativa semelhante à de seu colega Elias, recorreu à autoridade da professora como critério de correção da escrita:

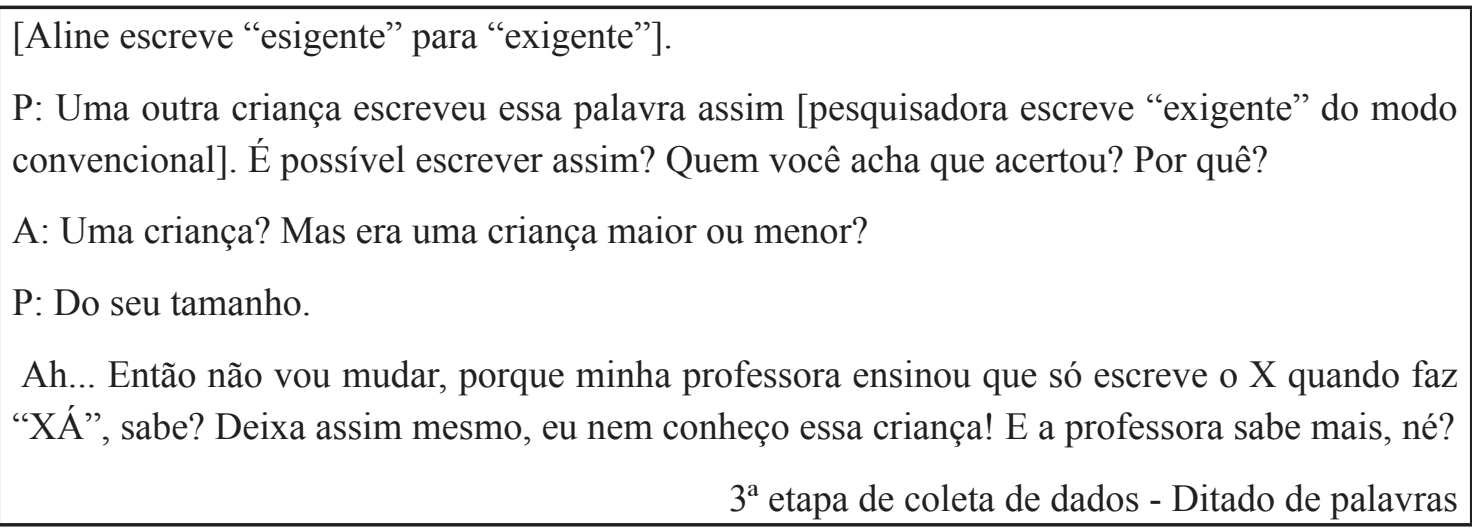

Em suas respostas, Aline buscou informações sobre o autor da escrita que lhe foi apresentada, de forma a decidir se essa "outra criança" era um locutor autorizado ou não. Com a resposta da pesquisadora, que tentou eliminar o critério de "tamanho" (supostamente atrelado à idade e ao grau conhecimento), ela preferiu garantir-se na interlocutora supostamente mais autorizada: a professora. A justificativa com base no que a docente "ensina" pareceu-lhe, definitivamente, mais confiável.

Nas produções textuais, outros exemplos dessa categoria surgiram. Um deles é o caso de Milena:

[Milena escreve "gão" para "grão"].

P: Se eu disser que nessa palavra está faltando uma letra, você consegue descobrir qual é?

M: Faltando? Ah é, está faltando o R. [Escreve "grão"]. É uma palavra um pouco difícil, mas a minha professora já me explicou que é assim que se escreve, eu que esqueci.

$3^{\mathrm{a}}$ etapa de coleta de dados - Reescrita de texto

Nas sessões anteriores, tanto nas escritas de listas quanto de textos, Milena escrevera "grão" de modo convencional. Portanto, é possível supor que seu "erro" tenha, de fato, sido uma distra- 
ção, e não um desconhecimento da norma ortográfica. De qualquer forma, para justificar a escrita convencional, ela utiliza a validação da professora, reconhecida como interlocutora autorizada.

\section{c) Escrita baseada em "imagem visual" da palavra}

A terceira categoria reúne casos em que as crianças justificaram suas escritas com base na "imagem visual" que já tinham das palavras. Em alguns casos, alegavam já terem visto a palavra em outro contexto ou suporte textual (em um livro, um cartaz, uma placa etc.); em outros, escreviam a palavra de duas maneiras e decidiam a partir da observação, alegando que, "vendo" a palavra, um dos modos lhes parecia "melhor" que o outro. Ao contrário da primeira categoria de repostas, nos quais predominavam os verbos "ouvir" e "escutar", nessa, predominaram os verbos "ver", "enxergar" e "olhar": assim como na primeira categoria, as crianças pediam muitas vezes para a pesquisadora repetir a palavra, para que pudessem discriminar melhor os sons, nesta, elas escreveram muitas vezes as palavras, para que pudessem vê-la. A seguir, um exemplo de resposta desse tipo:

[Elias escreve "principi" para "príncipe"].

P: Você escreveu "principi" do jeito que a gente fala. Será que existem palavras que a gente fala de um jeito e escreve de outro? Essa poderia ser uma delas?

E: Ah, existem muitas... [Olhando para a sua escrita, coça a cabeça, fica pensativo], Sabe, a gente está estudando a Bela Adormecida, e eu já vi o nome do príncipe Phillip... Eu preciso me lembrar. Ah não, esqueci do E, lá nos contos de fada tem o E e eu coloquei o I! Vou mudar! [Escreve "principe"].

$1^{\text {a }}$ etapa de coleta de dados - Ditado de palavras

Neste caso, Elias citou explicitamente o contexto de onde tirou a "informação visual" que subsidia a sua resposta. Mencionou o estudo de um conto visto na escola, buscou um dos personagens como referência e, com base nisso, modificou sua resposta, aproximando-se da escrita convencional (deixando apenas de colocar o acento). A atitude reflexiva até que ele pudesse fazer sua opção gráfica e a expressão de seu rosto ante a descoberta de uma base segura de escrita indicam que, de fato, ele buscava uma referência em "algo" já visto.

Ao citarem outros portadores, outras crianças não se limitaram à esfera escolar, recorrendo também a referências de escritas vistas fora da escola. Erick usa essa estratégia para justificar sua escrita de ervilha: 
[Erick escreve "ervilha" de modo convencional, mas, mesmo assim a pesquisadora testa a sua convicção sobre a ortografia da palavra].

P: Se eu disser que nessa palavra tem uma letra errada, você consegue descobrir qual é?

E: Não, eu sei que não tem nenhuma letra errada, porque eu como ervilha, e na lata vem escrito assim, eu sempre vejo, eu enxergo bem e eu me lembrei.

4a etapa de coleta de dados - Ditado de palavras

Em sua justificativa, Erick recuperou um suporte textual de seu cotidiano, recorrendo à sua memória visual para decidir a grafia da palavra. Mostrou-se seguro da escrita desde o início e, apesar de já ter conseguido explicitar a norma ortográfica de outros termos, aqui, ainda se valeu da referência visual.

Além da busca por lembranças de imagens visuais de escritas já vistas, alguns alunos utilizaram, nessa categoria, outro recurso: escreveram a palavra de duas formas diferentes, numa tentativa de lembrar qual delas lhes parecia mais familiar. Thiago é um desses exemplos:

[Thiago escreve "relanpago" para "relâmpago"].

P: Olhando para as letras que vêm antes e depois do N, você mudaria o jeito de escrever a palavra?

T: Eu quero me lembrar do livro de ciências, quando a gente estudou a diferença de trovão e relâmpago... [Escreve "trovao" e "relanpago". Logo abaixo, escreve "trovao" e "relampago". Demora-se observando as duas escritas]. É, acho que assim fica melhor! [Escreve "relampago"].

$2^{\mathrm{a}}$ etapa de coleta de dados - Ditado de palavras

Neste caso, Thiago sentiu a necessidade contextualizar a escrita e visualizar novamente as palavras para resgatar a imagem visual. Ele citou o suporte e o contexto onde a viu (livro didático de Ciências, no estudo de trovões e relâmpagos) e, para decidir, colocou ao lado da palavra "relâmpago" a palavra "trovão", provavelmente na tentativa de criar um contexto similar àquele em que vira a palavra pela primeira vez.

\title{
d) Escrita orientada pela norma ortográfica
}

\author{
plurais \\ Salvador, v. 5, n.3, p. 144-165, set./dez. 2020
}


A última categoria de respostas é justamente aquela em que as crianças justificaram sua escrita original - e também sua decisão pela mudança ou permanência após as intervenções - com base na norma ortográfica. Lançando mão de reflexões metalinguísticas, elas citaram a existência de regras, ainda que não soubessem explicá-las detalhadamente. A justificativa dada por Ricardo ilustra esta categoria:

[Ricardo escreve "moça" convencionalmente, mas, mesmo assim, a pesquisadora resolveu testar a sua convicção sobre a ortografia da palavra].

P: Uma outra criança escreveu essa palavra assim [pesquisadora escreve "mosa"]. É possível escrever assim? Quem você acha que acertou? Por quê?

R: Não, ela não pode escrever assim, porque senão ia ser que nem "casa", sabe? A gente não lê /casa/, lê "casa" [contrapondo os fonemas /s/ e /z/]. Então, se ela escreveu assim, a gente ia ler "moza", tem que ser o $\mathrm{C}$ com a cobrinha mesmo.

P: E se a criança escrevesse "mossa", podia ser?

R: Podia, mas ia ser estranho... É só ela comprar um leite condensado, que ela já ia saber (risos)!

$3^{\mathrm{a}}$ etapa de coleta de dados - Reescrita de texto

Em sua resposta, Ricardo demonstrou que a imagem visual da palavra também foi um recurso utilizado por ele, já que citou o leite condensado (cuja marca líder - "Moça"- vem estampada em tamanho grande no rótulo). Entretanto, esse critério não foi a principal base de sua resposta. Sem explicitar em termos técnicos, ele conseguiu explicar com muita clareza a norma ortográfica para leitura de $\mathrm{S}$ entre vogais, quando o grafema assume o valor do fonema $/ \mathrm{z} /$.

Outro exemplo dessa categoria foi a justificativa de Erick, na situação a seguir:

[Erick escreve "tempestade horivel" e a pesquisadora mostra a ele sua escrita].

P: Olhando para as letras que vêm antes e depois do $\mathrm{R}$, você mudaria o jeito de escrever a palavra?

E: Ah, lembrei! Já aprendi isso! Não é "horível", é "horrível" [contrapondo os fonemas /r/e /R/]. Se puser um R só no meio, fica "horível”, eu tinha escrito "horível”... A gente já até colocou isso no caderno de combinados ortográficos.

$4^{\mathrm{a}}$ etapa de coleta de dados - Reescrita de texto 
Erick havia escrito a palavra "horrível" de modo convencional no ditado de palavras, mas omitiu um R ao redigir o vocábulo em seu texto. Isso indica que, provavelmente, não se tratava do desconhecimento do modo convencional de se escrever. Outro indício de que ele conhecia a palavra foi o fato de ter colocado o $\mathrm{H}$ inicial, irregularidade que, em tese, é mais difícil para as crianças do que a regularidade contextual de uso de dois $\mathrm{R}$ entre vogais. Ao identificar seu erro, ele foi claro ao lembrar da regra: "no meio fica horível" (embora não tenha mencionado o fato de estar entre vogais, parece perceber isso de modo intuitivo). O menino mencionou ainda o estudo já realizado (“Já aprendi isso") e citou, inclusive, o "caderno de combinados ortográficos” (estratégia metodológica adotada pela escola para o ensino de ortografia).

Tendo explicitado as categorias encontradas para as justificativas de opções ortográficas, passamos ao estudo dos índices dessas ocorrências ao longo das cinco etapas de investigação.

\section{Percurso das justificativas na progressão do conhecimento ortográfico}

A cada etapa, foram obtidas 10 respostas por criança para a intervenção da pesquisadora nas respectivas dificuldades ortográficas (cinco para a sessão de ditado de palavras e cinco para a sessão de reescrita do texto). Como a quantidade de alunos participantes foi diferente a cada etapa, converteu-se o resultado final em índices percentuais, de forma a observar a evolução de cada categoria longitudinalmente:

Quadro 3 - Percentuais de respostas por categoria a cada etapa

\begin{tabular}{|c|c|c|c|c|}
\hline & $\begin{array}{c}\text { Escrita a partir da } \\
\text { pauta sonora }\end{array}$ & $\begin{array}{c}\text { Escrita validada } \\
\text { por interlocutor } \\
\text { autorizado }\end{array}$ & $\begin{array}{c}\text { Escrita baseada na } \\
\text { imagem visual }\end{array}$ & $\begin{array}{c}\text { Escrita orienta- } \\
\text { da pela norma } \\
\text { ortográfica }\end{array}$ \\
\hline $\mathbf{1}^{\text {a }}$ etapa & $53 \%$ & $30,80 \%$ & $9,20 \%$ & $6,70 \%$ \\
\hline $\mathbf{2}^{\text {a }}$ etapa & $38,50 \%$ & $34,20 \%$ & $18,50 \%$ & $8,50 \%$ \\
\hline $\mathbf{3}^{\text {a }}$ etapa & $21,10 \%$ & $27,80 \%$ & $29,40 \%$ & $21,70 \%$ \\
\hline $4^{\text {a }}$ etapa & $12,20 \%$ & $17,20 \%$ & $36,70 \%$ & $33,90 \%$ \\
\hline $5^{\text {a }}$ etapa & $7,80 \%$ & $10 \%$ & $25,50 \%$ & $56,60 \%$ \\
\hline
\end{tabular}

A evolução de cada categoria de respostas, observada de forma longitudinal, apresenta um percurso linear que, tanto na vertente ascendente como na descendente, e, ainda, nas relações entre

\section{plurais}


si, parecem bastante compreensíveis na progressão do conhecimento. Aquela em que as crianças justificam sua escrita a partir da pauta sonora apresenta um decréscimo conforme elas avançam na escolaridade: a cada etapa de coleta de dados, a quantidade de respostas dessa categoria diminui. Já os casos em que a escrita é justificada pelos ensinamentos ou exemplos de um interlocutor autorizado apresentam crescimento da primeira para a segunda etapa e, então, passam a decrescer também. Por sua vez, as respostas que se pautam na imagem visual que os alunos têm da palavra apresentam movimento ascendente da primeira à quarta etapa de coleta, diminuindo na quinta. Finalmente, as respostas que justificam a forma de grafar através da explicitação da norma ortográfica apresentam crescimento progressivo ao longo de todas as etapas pesquisa. O gráfico a seguir torna ainda mais explícitos esses percursos.

Gráfico 1 - Evolução longitudinal das categorias de respostas

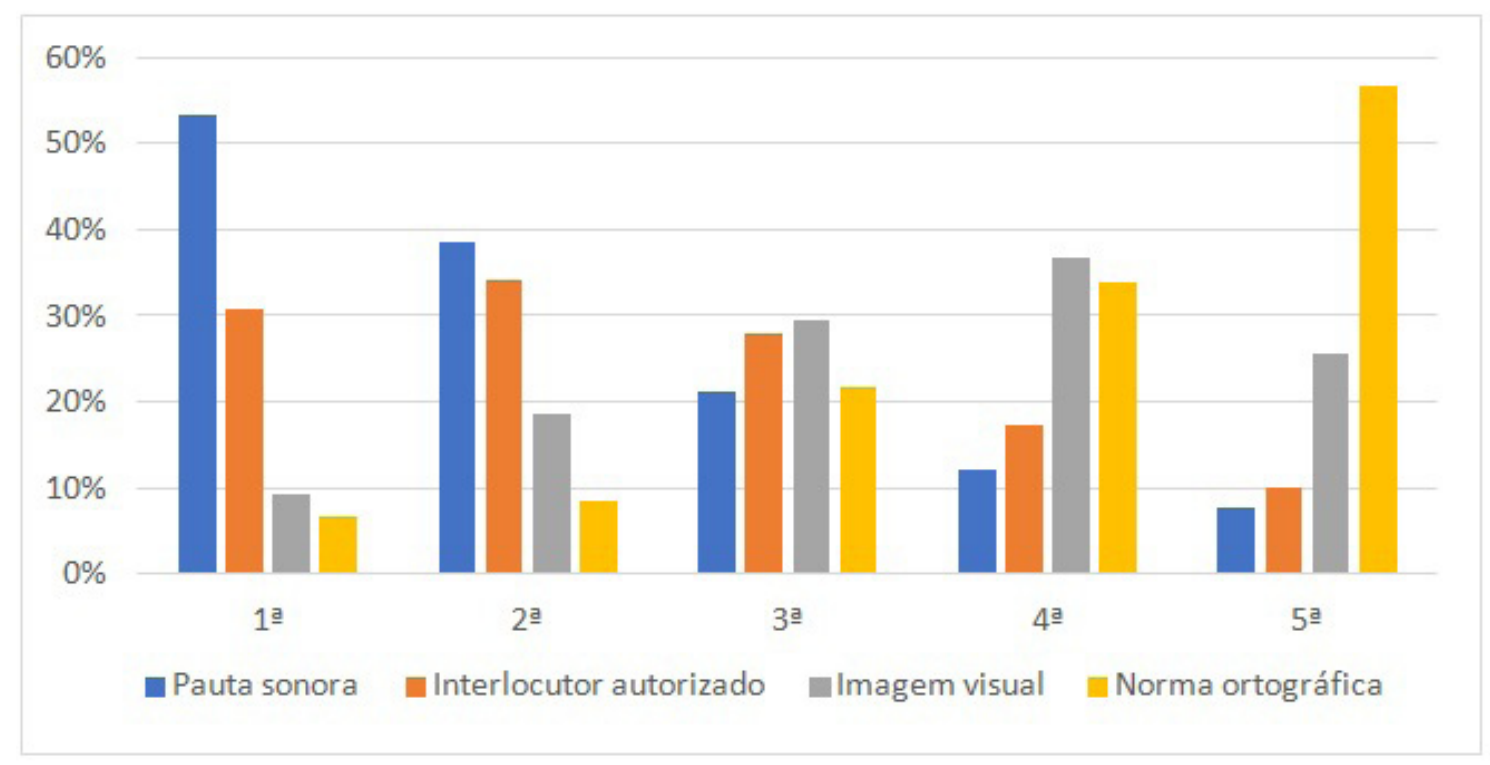

O gráfico demonstra, de forma inequívoca, o movimento da distribuição das quatro categorias. Nos dois extremos, estão os maiores índices percentuais encontrados: 53\% das crianças baseavam-se na pauta sonora para justificar suas grafias na primeira etapa, enquanto $56,6 \%$ delas utilizavam a norma ortográfica para explicar suas opções de escrita, na última. Em consonância 
com essas tendências, parece compreensível que a terceira etapa de coleta de dados, metade do percurso estudado, tenha trazido uma distribuição mais equitativa entre as categorias de respostas.

Embora nas duas primeiras etapas a maior parte das crianças tenha respondido às intervenções com base na pauta sonora, a diferença percentual registrada nos dois momentos já marca uma redução na segunda etapa. Observe-se também que a diferença entre essa categoria e a segunda maior (escrita validada por um interlocutor autorizado) diminuiu significativamente, chegando quase a uma equivalência na segunda etapa.

Da segunda para a terceira etapa (passagem do $2^{\circ}$ para o $3^{\circ}$ ano do Ensino Fundamental), registrou-se a mudança da categoria que, a princípio, tinha maior incidência. Na terceira e quarta etapas, enquanto as crianças cursavam o $3^{\circ}$ ano, predominaram as respostas baseadas na imagem visual que os alunos tinham das palavras. Essa categoria aumentou durante esse período, passando de uma quase equivalência com a dos interlocutores autorizados na terceira etapa, mas distanciando-se dela na quarta, justamente em função da progressão do conhecimento, que foi se tornando mais autônomo.

A próxima mudança de ano escolar das crianças coincide, mais uma vez, com a mudança na categoria de respostas predominante: na quinta etapa coleta de dados, quando os alunos já se encontravam no $4^{\circ}$ ano do Ensino Fundamental, passam a prevalecer as respostas em que os alunos explicitaram as normas ortográficas, uma evidência do crescimento da consciência metalinguística.

Em uma outra possível configuração de análise dos dados, vale destacar a diferença nos índices de acertos nos dois eixos estudados - sempre (em todas as etapas) maior no ditado do que nas reescritas de texto. Essa diferença justifica-se porque, como se sabe, a produção textual, em relação à escrita de palavras isoladas, amplia as frentes de elaboração para as quais os sujeitos devem estar atentos, o que aumenta a complexidade da tarefa. Enquanto no ditado o aspecto notacional é a principal fonte de atenção, na redação, o sujeito deve se preocupar também com a integridade do conteúdo, o fio condutor da narrativa, a organização e coesão do texto, a adaptação ao interlocutor de modo a garantir a sua inteligibilidade etc. Mesmo assim, vale registrar que a diferença do índice de acertos no ditado e na reescrita foi menor nos dois períodos extremos da coleta: na primeira etapa porque a escrita, em si, ainda representava uma grande dificuldade para os alunos (apresentando, portanto, mais erros nas duas atividades); e, pela lógica inversa, na $5^{\text {a }}$

\footnotetext{
plurais

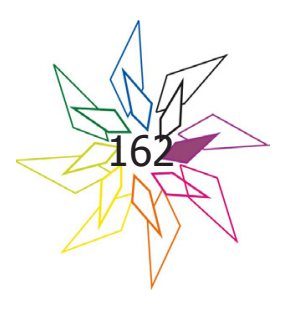


etapa, justamente porque nesse momento o escrever estava mais estabilizado (portanto, com menos erros nas duas atividades).

A análise desses percursos parece demonstrar que a progressão dos alunos não se dá somente na mudança nas grafias, quando se aproximam paulatinamente da escrita convencional, mas também no modo como pensam para elaborar e justificar suas escritas, aproximando-se gradativamente dos modos mais convencionais e de reflexões mais autônomas e conscientes. Assim, mesmo com a presença e dispersão de categorias evocadas em cada etapa da pesquisa, fica delineado um continuum no processo de aprendizagem com base no que prevalece em cada etapa da escolaridade.

\section{Considerações: dos processos de aprendizagem às implicações pedagógicas}

Ainda que de forma não exaustiva, a análise dos dados permite algumas conclusões sobre a construção da ortografia que, como não poderia deixar de ser, remetem a importantes implicações pedagógicas, funcionando como subsídios para se repensar as práticas de ensino. De fato, ao compreender o percurso trilhado pelas crianças em seu processo de aprendizagem da ortografia e suas estratégias na busca de referências ou de procedimentos reflexivos, o professor pode assumir uma postura investigativa, a fim de identificar não apenas o índice de escritas convencionais registrado por seus alunos, mas também - e principalmente - interferir produtivamente na progressão desse conhecimento. Assim, considerando as relações entre processos cognitivos e diretrizes pedagógicas, alguns pontos merecem destaque.

Em primeiro lugar, vale defender a construção do conhecimento ortográfico como um esforço travado com base em diferentes caminhos de elaboração. Trata-se de um processo que, mais uma vez - se considerarmos os estudos de tantos outros aspectos da psicogênese da língua escrita - comprovam a inadequação de princípios ainda arraigados na cultura escolar: "a aprendizagem como um percurso linear, fixo e cumulativo"; "a aprendizagem como como consequência direta do ensino"; "o ensino projetado a priori e calcado na lógica do adulto, isto é, incapaz de considerar o ponto de vista do sujeito-aprendiz e a sua dinâmica de construção cognitiva"; e "o ensino planejado de modo inflexível, dosado em etapas do mais fácil para o mais difícil”. De fato, quando se coloca a criança no centro da aprendizagem e, no caso específico deste estudo, quando se compreende seus "tateios cognitivos" na busca pela escrita convencional, evidencia-se a complexidade do papel do professor, entendendo a intervenção pedagógica como prática flexível, diversificada, investigativa e construtiva também na perspectiva docente. $\mathrm{O}$ desafio do professor não é simplesmente ensinar (como quem apenas transmite

\section{plupais}


conhecimentos), mas principalmente, em conjunto com seus alunos, colocar-se como um produtor ativo do trabalho em sala de aula.

Nos referidos caminhos de construção do conhecimento ortográfico, observa-se, em segundo lugar, uma tendência de progressiva reflexão, autonomia e abstração linguística. A criança recém-alfabética, que tende a se apegar mais à discriminação auditiva buscando a relação direta fonema-grafema, passa por referências heterônomas (a palavra segundo interlocutores autorizados ou registrada por outros sob a forma de imagem visual), chegando a critérios de compreensão da língua para lidar com a ortografia de modo mais autônomo. A compreensão desse percurso (um verdadeiro continuum de progressiva aproximação com o convencional) traz ao professor o desafio de lidar com diferentes critérios de interação, valorizando-os não como etapas sucessivas e previsíveis de ensino, mas como caminhos que se sobrepõem (ainda que com diferentes ênfases) na problematização da língua. Assim, não se pode dizer que exista uma interação adulto-criança melhor ou pior; o que existe é a interlocução inteligente, pensada em diferentes vias, para diferentes alunos e em contextos específicos.

Em terceiro lugar, vale dizer que a progressão da aprendizagem da ortografia não se manifesta apenas pelo aumento do índice de "acertos" na escrita. Conforme avançam, as crianças não apenas escrevem mais vezes de forma convencional, como também alteram e ampliam a maneira como explicam, justificam ou validam o modo de grafar as palavras. Ao longo dessa trajetória, ainda que a escrita não convencional seja baseada em critérios nem sempre eficientes, o simples fato de a criança buscar outros critérios e de ampliar referências pessoais de validação já é, em si, um indício e, ao mesmo tempo, um componente de evolução na medida em que comprova a ampliação de caminhos reflexivos. Assim, justifica-se, na escola, a pertinência de revisão dos mecanismos de acompanhamento e de avaliação dos estudantes, podendo considerar, para além dos acertos e erros, aspectos nem sempre valorizados pelos professores (como são os casos dos processos de elaboração cognitiva ou das descoberta de estratégias que, bem ou mal, sustentam uma opção de escrita).

O quarto aspecto de destaque nos obriga a reconhecer que a assimilação da ortografia não pode ser entendida pala dicotomia estável de "conhecer e aplicar" e "não conhecer e não aplicar". Isso significa que escrever convencionalmente em um contexto (por exemplo, em um ditado) não garante a correção em todos os contextos (ditados, produções de textos de autoria, reescritas etc.). $\mathrm{Na}$ tentativa de explicar essa oscilação, mais uma vez, é preciso considerar o ponto de vista do sujeito: um "escritor" que opera em diferentes planos de reflexão, em diferentes contextos de produção, sempre buscando atender aos apelos do propósito da escrita ou da prática comunicativa. Como frentes de processamento cognitivo, os diferentes conhecimentos sobre a escrita levam algum tempo para

\section{plurais}

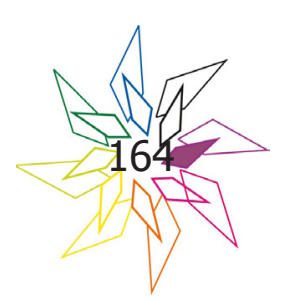


se estabilizarem, e se articularem em produções cada vez mais eficientes. Isso traz ao professor a necessidade de propor atividades diversificadas a fim de estimular/provocar/desafiar o aluno a partir de diferentes demandas e apelos da cultura escrita.

Com base nos aspectos mencionados, fica evidente que, no contexto da sala de aula, partindo da perspectiva dos sujeitos - suas estratégias de busca e de validação da base ortográfica, seus esforços para a ampliação das alternativas reflexivas, seus caminhos de progressão rumo a comportamentos mais autônomos do escrever - justifica uma escola capaz de lidar com a complexidade inerente à língua, visando não apenas a aquisição e apropriação da escrita mas, sobretudo, a constituição do sujeito-autor e o fortalecimento da postura reflexiva em face do conhecimento.

\section{REFERÊNCIAS}

COLELLO, Silvia Mattos. Gasparian. A escola que (não) ensina a escrever. São Paulo: Summus, 2012.

FERREIRO, Emilia. Atualidade de Jean Piaget. Porto Alegre: Artmed: 2001.

GERALDI, João Wanderley. O texto na sala de aula. São Paulo: Assoeste, 2006.

MORAIS, Artur Gomes. Ortografia: ensinar e aprender. São Paulo: Ática, 2003.

NÓBREGA. Maria José. Ortografia. São Paulo: Melhoramentos, 2013.

WEISZ, Telma; SANCHEZ, Ana. O diálogo entre o ensino e a aprendizagem. SP: Ática, 2001.

Recebido em: 20 de julho de 2020.

Inserido em: 15 de outubro de 2020.

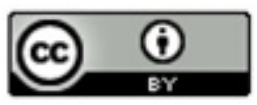

Esta obra está licenciada com uma Licença Creative Commons Atribuição 4.0 Internacional.

\section{plurais}

